\title{
Spontaneous and induced components of salinity preference behaviour in Carcinus maenas
}

\author{
C. Ameyaw-Akumfi* \& E. Naylor \\ School of Animal Biology, University College of North Wales, Bangor, Gwynedd, United Kingdom
}

\begin{abstract}
Mark and recapture experiments showed that shore crab Carcinus maenas in an estuary were capable of remaining there for at least $6 \mathrm{~d}$ and were potentially exposed to extreme changes in salinity over successive tidal cycles. Behavioural responses of $C$. maenas to salinity were studied in choice-chamber experiments, in some of which locomotor activity and a crab"s position in the choice chambers were recorded continuously. In multiple-choice and 2-choice experiments, crabs responded to salinity differences of as little as 4 to $6 \% \mathrm{~S}$ over a period of 4 to $5 \mathrm{~h}$. C. maenas has a 'preferred' salinity range with a lower limit of about $27 \% \mathrm{~S}$ ( $\equiv 80 \% \mathrm{SW})$, which is shown to be achieved partly by avoidance behaviour in the form of sustained halokinesis, though this was exhibited most markedly when both salinities offered were below about $17 \% \mathrm{~S}$. In the salinity range 17 to $27 \% \mathrm{~S}$ avoidance of the lower salinity in a pair offered appears to follow mainly from the spontaneous pattern of locomotor activity, which occurs even in controls when crabs are presented with water of $34 \% \mathrm{~S}$ in each half of a choice chamber.
\end{abstract}

\section{INTRODUCTION}

The shore crab Carcinus maenas (L.) is known to survive indefinitely in salinities far below $34 \% \mathrm{~S}$ (Duvel 1925, Crothers 1968); it is a typical euryhaline crab classified as a hyperosmotic regulator (Rankin \& Davenport 1981, Davenport 1985). In this species, as in other organisms (Davenport 1985), more research effort has been directed towards elucidating physiological rather than behavioural responses to changed salinity, but the crab is known to avoid both hyposaline and hypersaline media by increased locomotor activity, defined as halokinesis (Taylor \& Naylor 1977, Thomas et al. 1981). In those behavioural experiments $C$. maenas was shown to have a preferred salinity range of 80 to $120 \%$ SW where $100 \%$ SW is $34 \%$ S. Salinities separated by $10 \%$ were not distinguished, but differences of $25 \%$ were clearly distinguished on choices up to and including 50 vs $75 \% \mathrm{SW}$, and above $125 \% \mathrm{SW}$, given the choice of 125 vs $150 \%$ SW. In such cases crabs avoided the salinity farthest from $34 \% \mathrm{~S}$. Those experiments were, however, carried out over a relatively short time-scale $(2 \mathrm{~h})$ with observations made only intermittently. The present experiments were

\footnotetext{
* Present address: Department of Zoology, University of Cape Coast, Cape Coast, Ghana
}

designed to observe crabs for longer periods, in some cases using an electronic recording technique to measure continuously the movements of crabs between 2 salinity test chambers. This permits a more detailed study of the time-basis of the behavioural responses of crabs to salinity perturbations, and allows more critical evaluation of the halokinesis hypothesis proposed by Taylor \& Naylor (1977).

The involvement of tidal changes of salinity as a factor inducing rhythmic locomotor activity in Carcinus maenas and in entraining endogenous aspects of such behaviour has been reviewed by Naylor (1985). It has been established experimentally that walking activity of crabs increases with lowering of salinity (Bolt \& Naylor 1985) and that low salinity might, therefore, be expected to induce high locomotor activity in submerged crabs at low tide in estuarine environments. However, little detailed information is available on how crabs respond behaviourally to changes in salinity in their environment. Crabs are known to exhibit tidal and seasonal variation in their distribution in various coastal regions (Naylor 1962, Crothers 1967). More recently, too, Dare \& Edwards (1981), using an underwater video technique, recorded movement of a population of $C$. maenas onto a bed of Mytilus edulis at high tide and away from the beach with the ebbing tide. Such studies have, however, 
addressed the problem mainly in open-coast crabs in which behavioural responses are mostly related to changes in tidal height. In the present study attempts have been made to observe the extent of movement of crabs in an estuary, and to assess the behavioural responses of such crabs to salinity change.

\section{MATERIALS AND METHODS}

Field observations. The site chosen for the field study was the estuary of the River Gwyrfai, near Caernarfon, North Wales, U.K. $\left(53^{\circ} 06^{\prime} \mathrm{N}, 4^{\prime} 22^{\prime} \mathrm{W}\right)$, which virtually empties of seawater at low tide. At low tide the river runs over a sandy estuarine area for about $2.5 \mathrm{~km}$ from the approximate limit of tidal influence to the point where it enters the sea (Ordnance Survey Map 115). Mark and recapture experiments were carried out in January and April of 1985. Male crabs measuring 35 to $55 \mathrm{~mm}$ in cephalothorax width were collected in the estuary and marked by clipping the tips of their antero-lateral teeth on either side. Marked animals were released near the limit of tidal influence during high tide.

During the low tide preceding the crabs' release, 3 groups of $5 \mathrm{crab}$ traps containing fish bait were placed across the width of the freshwater outflow (15 to $50 \mathrm{~m}$ ) at 3 localities within the estuary. These were approximately $0.5,1.5$ and $2.0 \mathrm{~km}$ respectively below the release point, the last being $0.5 \mathrm{~km}$ from the sea. The traps were inspected during the 6 succeeding daytime low tides and the numbers of marked crabs were recorded. The crabs were not replaced.

Choice chamber experiments. A multiple-choice chamber was constructed of marine plywood, sprayed with water-resistant paint. This consisted of a tank measuring $40 \times 160 \times 40 \mathrm{~cm}$ high, the floor of which was constructed as 4 choice chambers each measuring $40 \mathrm{~cm}$ wide and $40 \mathrm{~cm}$ long. Each chamber was V. shaped in vertical section, sloping inwards to a maximum depth of $15 \mathrm{~cm}$ when just filled with water. The compartments were filled with water of different salinities and aerated through air stones placed in the chambers. Before and after each trial, the salinity in each chamber was measured using a Salinity Temperature Bridge Type M.0.5. Salinities never varied by more than $0.5 \%$ S over an experimental period of $12 \mathrm{~h}$. Since single crabs and small groups gave similar results, crabs were introduced in batches of 8 into one of the 4 chambers on a random basis and at the end of 6 or $12 \mathrm{~h}$ their distribution in the test chambers was recorded. Two sets of 15 experiments, all with different crabs, were run, one with chambers containing water of salinities $5,11,17$ and $22 \%$ and the other with 22 , 28,34 and $40 \%$ S. Therefore, 120 crabs were used in each set of these preliminary experiments.
A 2-choice chamber, derived from that of earlier workers (McLusky 1970, Davenport 1972, Thomas et al. 1981) was also used. A plastic tank measuring 130 $\times 70 \times 35 \mathrm{~cm}$ high was modified by the addition of a concrete floor which sloped upwards from each side at about $30^{\circ}$ to form a central ridge which extended along the length of the tank. Three movable wooden partitions were placed across the width of the tank at 16.5 $\mathrm{cm}$ intervals thus providing 4 replicate compartments. Holes $1 \mathrm{~cm}$ in diameter were drilled through each partition to allow free flow of water between the 4 compartments. Sheets of perspex were used to cover each half of the tank, and from these were suspended 8 stainless steel, pivoted arms each in the form of an inverted ' $T$ '. Pieces of silicone rubber tubing each $3 \mathrm{~cm}$ in length and $2 \mathrm{~mm}$ in diameter were attached to the horizontal arms of each ' $\mathrm{T}$ ' piece which measured 16 $\mathrm{cm}$. This allowed a clearance of about $1 \mathrm{~cm}$ between the tips of the tubing pieces and the concrete floor, and the arms were moved when touched by a moving crab. At the upper end of each steel arm, a small brass flag was attached to interrupt an infra-red photo emitter/ detector, signals from which were recorded on an 8channel event recorder.

Crabs used in all these experiments measured 35 to $60 \mathrm{~mm}$ carapace width. They were collected in spring from the field study area and maintained in the laboratory in $34 \% \mathrm{~S}$ at $15^{\circ} \mathrm{C}$ for at least 1 wk before use. The experimental chambers were maintained at $14 \pm 1{ }^{\circ} \mathrm{C}$ and under constant illumination provided by fluorescent tubes $(75 \mathrm{~W})$ at a distance of 3 to $4 \mathrm{~m}$.

\section{RESULTS}

\section{Mark and recapture experiments}

Crabs dispersed quite rapidly from the release point near the limit of tidal influence to extend over the whole of the tidal reach of the estuary (Table 1). Indeed a few clearly travelled a linear distance of about $2.0 \mathrm{~km}$ during the $6 \mathrm{~h}$ period from the time of release at high tide to the time of the next low tide. It is unlikely that all the crabs moved out of the estuary immediately after release and re-entered it on each succeeding low tide. The most likely explanation of these results is, therefore, that many crabs remained in the estuary for the $6 \mathrm{~d}$ of each experiment and were thus exposed to potential variations in salinity from that of full seawater to virtually freshwater over each tidal period. There are slight differences in the recapture data between January and April (Table 1) but whether these are random or have a biological basis remains to be investigated. 
Table 1. Carcinus maenas. Numbers of marked crabs captured daily at low tide in baited traps placed $0.5,1.5$ and 2.0 $\mathrm{km}$ respectively below a release point in the Gwyrfai estuary, North Wales. (a) 600 marked crabs released at high tide on 15 Jan 1985 (Day 1); (b) 500 released at high tide on 19 Apr 1985 (Day 1)

\begin{tabular}{|crrr|}
\hline Day & \multicolumn{3}{c|}{ Distance from release point } \\
& $0.5 \mathrm{~km}$ & $1.5 \mathrm{~km}$ & $2.0 \mathrm{~km}$ \\
\hline a. January & & & \\
1 & 10 & 6 & 6 \\
2 & 4 & 4 & 3 \\
3 & 6 & 2 & 2 \\
4 & 8 & 4 & 2 \\
5 & 10 & 2 & - \\
6 & 6 & 3 & 1 \\
7 & 3 & 1 & 1 \\
Totals & 47 & 22 & 15 \\
b. April & & & \\
1 & 2 & 4 & 1 \\
2 & - & - & - \\
3 & 2 & 2 & 5 \\
4 & - & 2 & - \\
5 & - & 1 & - \\
6 & - & 2 & 1 \\
7 & 1 & - & 8 \\
Totals & 5 & 11 & \\
\hline
\end{tabular}

\section{Multiple-choice experiments}

Fig. 1a shows the percentage distribution for a total of 120 crabs used in 15 replicate experiments in January, offered a choice of salinities of $5,11,17$ and $22 \%$ $\mathrm{S}$. Crabs showed a clear preference for the highest salinity $\left(\chi^{2}=97.17, p<0.05\right)$ with an even greater percentage occurring in $22 \%$ S after $12 \mathrm{~h}\left(\chi^{2}=145.18\right.$, $p<0.05$ ). Fig. $1 b$ shows the percentage distribution for a total of 120 crabs in 15 replicate experiments, offered a choice of salinities of 22, 28, 34 and $40 \%$ S. After $6 \mathrm{~h}$ there was no statistically significant difference in the number of crabs in the 4 chambers $\left(\chi^{2}=3.01, p>0.05\right)$ but after $12 \mathrm{~h}$ there was a significant preference for $34 \% \mathrm{~S}\left(\chi^{2}=12.67, \mathrm{p}<0.05\right)$. Clearly, salinity increments of as little as 5 to $6 \%$ are detected by Carcinus maenas, though at salinities of around $34 \% \mathrm{~S}$ preferences take longer than $6 \mathrm{~h}$ to become established.

\section{Two-choice experiments}

Further experiments were then carried out to define more accurately the sensitivity and time-course of these salinity choice responses. In initial experiments using water of 13 and $17 \% \mathrm{~S}$ in the 2 halves of each of the 4 compartments of the choice chamber, 5 batches of 4 crabs were first introduced into the lower of the 2

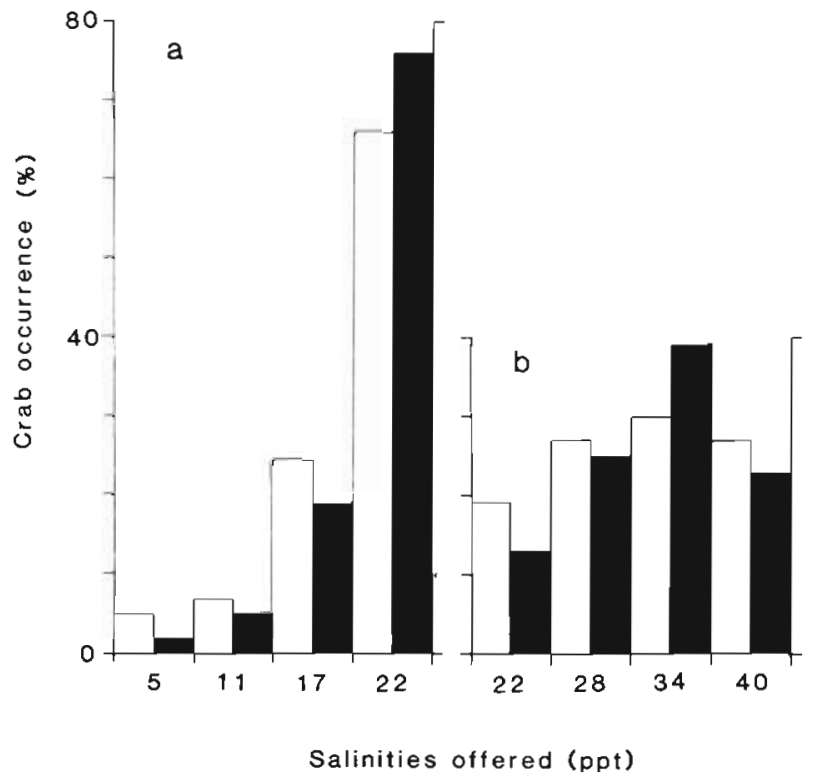

Fig. 1. Carcinus maenas. Percentage distribution of crabs in the 4 compartments of a multiple choice chamber after $6 \mathrm{~h}$ (open bars) and $12 \mathrm{~h}$ (black bars) with salinities of (a) 5, 11, 17 and $22 \% \mathrm{~S}$, and (b) $22,28,34$ and $40 \% \mathrm{~S}$ in the 4 compartments. Fifteen experiments were carried out in each of the 2 sets of conditions, each experiment using 8 crabs introduced into one of the 4 chambers on a random basis

salinities. The experiment was repeated with 5 further groups of 4 crabs placed separately in the 4 compartments of the choice chamber, which contained water of $17 \% \mathrm{~S}$. The time spent by each crab in each half of the choice chamber was recorded continuously over a period of $12 \mathrm{~h}$ (Fig. 2). Under the conditions of this experiment with crabs previously acclimated to $34 \% \mathrm{~S}$, a choice for the higher of the 2 salinities offered took 4 to $5 \mathrm{~h}$ and was clearly well established after $12 \mathrm{~h}$.

Subsequent 2-choice experiments using a range of pairs of salinities were run for $12 \mathrm{~h}$. Five replicate experiments were carried out, each with 4 separately recorded crabs; they were placed initially in the salinity of a pair that was farthest from $34 \% \mathrm{~S}$. The percentage time spent by each crab in each half of the choice chamber was then calculated over the total $12 \mathrm{~h}$ recording period, giving a set of 20 paired values for the 20 crabs used for each of the pairs of salinities tested (Table 2). Over the $12 \mathrm{~h}$ time-scale of the experiments, it is clear that Carcinus maenas made statistically significant behavioural choices between pairs of salinities with differences as little as $4 \%$. The only non-significant comparisons were in the control groups ( 34 vs $34 \%$ S) and in the groups offered 34 vs $40 \%$ S. In all cases where statistically significant choices were made, the crabs selected the salinity in the pair nearest to that of seawater $(34 \% \mathrm{~S})$. 


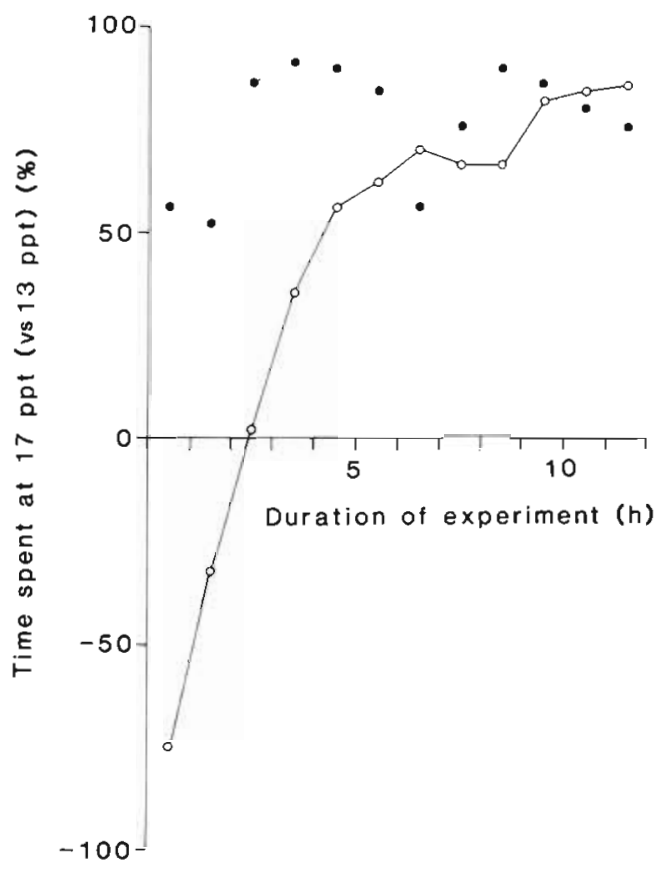

Fig. 2. Carcinus maenas. Hourly percentage time spent in water ot $17 \%$ S by 10 groups of 4 crabs in choice-chamber experiments, with salinities of 17 and $13 \% \mathrm{~S}$ in the $2 \mathrm{com}$ partments of the choise-chamber. At the start of the experiments 5 groups of 4 crabs were placed in the $13 \%$ S chambers (O) and 5 in the $17 \% \mathrm{~S}($

\section{Salinity-induced kinesis}

The observations presented so far could be explained in behavioural terms if Carcinus meanas showed increased locomotor activity in salinities different from $34 \%$ S, that is if crabs exhibit halokinesis as postulated by Taylor \& Naylor (1977).
That hypothesis has been tested in the present study by recording the number of transits made by crabs between choice chambers when offered a variety of pairs of salinities in the choice chamber. The results of these experiments (Table 3) show that in pairs of salinities with the higher value up to around $17 \%$ S, total locomotor activity is significantly greater than in the controls, despite the fact that in such cases the crabs spend more time at the higher of the 2 salinities in a pair (Table 2). In contrast, when offered a choice of 9 vs $34 \%$ S the crabs showed significantly less activity than controls; after initial high activity such crabs clearly avoided $9 \% \mathrm{~S}$ (Table 2 ). In all the other pairs of salinities offered (Table 3), with differences of 4 to $17 \%$ within the range 17 to $40 \% \mathrm{~S}$, there were no significant differences in the locomotor activity of the crabs when compared with controls. This occurred despite the fact that in all but one of the pairs of salinities used, the crabs spent significantly more time at the salinity nearest to $34 \%$ (Table 2). The results presented in Table 3 clearly give some support to the hypothesis of halokinesis in C. maenas, suggesting a behavioural mechanism by which very low salinities are avoided. However, the mechanism of choice between pairs of salinities in the range 17 to $40 \% \mathrm{~S}$ still remains to be considered.

Finally, further evidence of behavioural avoidance of low salinity was obtained when crabs offered a choice between 5 and $9 \% \mathrm{~S}$ spent considerable periods in the shallowest parts of $9 \% \mathrm{~S}$ chamber, partially exposed to air. This also occurred to some extent in crabs offered a choice of 9 and $13 \%$ S, despite the fact that both chambers were well aerated. Experiments were, therefore, carried out on crabs offered a choice of water of $9 \% \mathrm{~S}$ and moist air. The results of that experiments and of a control experiment with crabs offered

Table 2. Carcinus maenas. Percentage time spent by individual crabs recorded in batches of 4 in 5 replicate experiments, each over a $12 \mathrm{~h}$ period, in each of 2 chambers containing water of different salinity

\begin{tabular}{|c|c|c|c|c|c|c|}
\hline \multicolumn{2}{|c|}{ Salinity $(\%$ S) } & \multirow{2}{*}{$\begin{array}{c}\text { Salinity } \\
\text { difference }(\%)\end{array}$} & \multicolumn{2}{|c|}{ Mean percentage time } & \multirow{2}{*}{$\begin{array}{c}\text { t-test } \\
\text { value }(n=20)\end{array}$} & \multirow[t]{2}{*}{$\mathrm{p}$} \\
\hline Chamber A & Chamber B & & Chamber A & Chamber B & & \\
\hline 34 & 34 & 0 & 58.21 & 41.79 & 1.304 & $>0.05$ \\
\hline 5 & 9 & 12 & 8.54 & 91.46 & 23.198 & $<0.0001$ \\
\hline 9 & 13 & 12 & 8.98 & 91.02 & 24.267 & $<0.0001$ \\
\hline 13 & 17 & 12 & 5.90 & 94.10 & 14.574 & $<0.001$ \\
\hline 17 & 21 & 12 & 23.71 & 76.29 & 8.170 & $<0.001$ \\
\hline 25 & 29 & 12 & 24.03 & 75.97 & 2.415 & $<0.05$ \\
\hline 29 & 34 & 15 & 28.75 & 71.25 & 4.109 & $<0.001$ \\
\hline 40 & 34 & 18 & 47.18 & 52.82 & 1.009 & $>0.05$ \\
\hline 17 & 25 & 24 & 12.44 & 87.55 & 7.836 & $<0.0001$ \\
\hline 42.5 & 34 & 25 & 16.61 & 83.29 & 7.904 & $<0.001$ \\
\hline 45 & 34 & 26 & 16.88 & 83.12 & 6.949 & $<0.0001$ \\
\hline 29 & 40 & 32 & 29.00 & 71.00 & 2.725 & $<0.05$ \\
\hline 17 & 34 & 50 & 28.71 & 71.29 & 4.576 & $<0.001$ \\
\hline 9 & 34 & 74 & 1.74 & 98.26 & 37.24 & $<0.0001$ \\
\hline
\end{tabular}


Table 3. Carcinus maenas. Average numbers of transits from one half of experimental chamber to the other in individual crabs over $24 \mathrm{~h}$ during paired salinity tests compared with transits when seawater $(34 \% \mathrm{~S})$ was placed in the 2 chambers of the test apparatus. Twenty crabs were tested in each pair of salinities

\begin{tabular}{|c|c|c|c|c|c|c|}
\hline \multicolumn{2}{|c|}{ Pairs of salinities tested (\%o S) } & \multirow{2}{*}{$\begin{array}{c}\text { Salinity } \\
\text { difference }(\%)\end{array}$} & \multicolumn{2}{|c|}{ Mean transits (SD) } & \multirow{2}{*}{\multicolumn{2}{|c|}{$\frac{\begin{array}{c}\text { t-test } \\
\text { values }\end{array}}{\text { Control }}$}} \\
\hline 34 & 34 & & 26.50 & $(12.6)$ & & \\
\hline 5 & 9 & 12 & 69.81 & $(56.5)$ & 2.368 & $<0.05$ \\
\hline 9 & 13 & 12 & 52.67 & $(26.7)$ & 1.987 & $<0.05$ \\
\hline 13 & 17 & 12 & 54.92 & (34.9) & 2.257 & $<0.05$ \\
\hline 17 & 21 & 12 & 31.41 & $(33.8)$ & 0.657 & $>0.05$ \\
\hline 25 & 29 & 12 & 27.67 & $(15.7)$ & 0.023 & $>0.05$ \\
\hline 29 & 34 & 15 & 24.91 & $(13.5)$ & 0.657 & $>0.05$ \\
\hline 34 & 40 & 18 & 40.79 & $(51.6)$ & 0.770 & $>0.05$ \\
\hline 17 & 34 & 50 & 15.46 & $(10.5)$ & 1.352 & $>0.05$ \\
\hline 9 & 34 & 74 & 9.25 & ( 6.4) & 2.173 & $<0.05$ \\
\hline
\end{tabular}

the choice of 9 and $34 \% \mathrm{~S}$ in the 2 chambers (Fig. 3), indicate evacuation of the $9 \% \mathrm{~S}$ chamber by the third hour of each experiment.

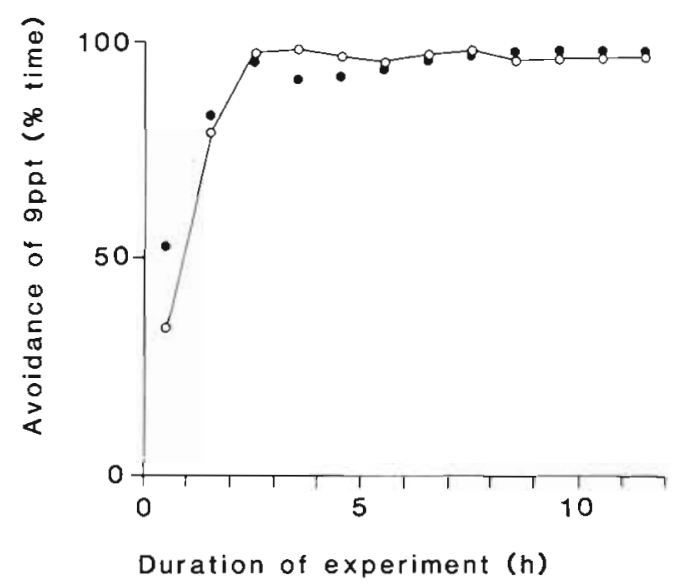

Fig. 3. Carcinus maenas. Hourly percentage time spent in water of $34 \% \mathrm{~S}$ in choice chamber experiments with salinities of 9 and $34 \% \mathrm{~S}$ in the 2 compartments of the choice chamber $(\bullet)$. Hourly percentage time spent in moist air in choicechamber experiments with a salinity of $9 \% \mathrm{~S}$ in one compartment of the choice chamber and filter paper moistened with water of $9 \% \mathrm{~S}$ in the other $(0)$. In each case 5 batches of 4 crabs were tested and placed initially into $9 \% \mathrm{~S}$

\section{DISCUSSION}

The occurrence in estuaries of the intertidal crab Carcinus meanas is well documented in general terms (Broekhuysen 1936, Muus 1967, Wolf \& Sandee 1971. Warner 1977) and is confirmed in detail in the present study. The mark and recapture experiments reported here clearly suggest that individuals moved freely in an estuary, covering distances of up to $2 \mathrm{~km}$ in $6 \mathrm{~h}$ which are greater than those reported for the larger portunid crab Scylla serrata by Hill (1978). Even so, many $C$. maenas clearly remained for long periods in an estuary which empties of seawater at low tide. In such localities, as in intertidal pools where freshwater input at low tide may be substantial, there would be clear advantages to crabs that exhibit behavioural responses permitting them where possible to avoid unfavourable salinities (Thomas et al. 1981), either by moving to higher salinities or by leaving the water to hide beneath stones or to burrow. The suggestion that they achieve this at least partly by halokinesis (Taylor \& Naylor 1977) is strongly supported by the present results.

Such an interpretation of the responses of crabs to salinities well below or above ambient salinity also explains the patterns of locomotor activity expressed by Carcinus maenas exposed to extensive cyclical changes of salinity. In square wave (Taylor \& Naylor 1977) and sine wave (Bolt \& Naylor 1985) patterns of salinity change of tidal (ca $12 \mathrm{~h}$ ) periodicity, C. maenas show pronounced exogenous locomotor responses to episodes of reduced salinity. In contrast, repeated exposure to episodes of $34 \% \mathrm{~S}$ induce smaller outbursts of locomotor activity, but these are shown to entrain the underlying circatidal locomotor rhythm of the crabs (Taylor \& Naylor 1977, Bolt \& Naylor 1985).

In the literature there are a number of reports of the discriminatory behaviour of crustaceans when offered pairs of salinities in choice experiments, particularly in relation to the limits of their physiological tolerance of high and low salinities. Thus Carcinus maenas (Thomas et al. 1981) and the amphipod Corophium volutator (McLusky 1970) have both been shown to have a preferred range of salinities well within their range of physiological tolerance. In contrast, the anomuran crabs Porcellana platycheles and P. longicornis exhibited salinity preference behaviour only at salinities outside their zone of physiological tolerance (Davenport 1972). All these workers, like Lagerspetz \& Mattila (1961), sought to assess the level of seawater dilution at which discriminatory behaviour 
first occurs, and/or the threshold of discrimination when pairs of salinities are offered. Most workers have used the distribution of crabs in choice chambers after a set interval of time as a measure of these discriminatory processes. In C. maenas, for example, Thomas et al. (1981) showed that in such behavioural terms the preferred salinity range was 27 to $41 \%$ S ( 80 to $120 \%$ SW). In paired tests salinity differences of $8.5 \%$ ( $25 \%)$, but not $3.4 \%$ o ( $\equiv 10 \%)$, induced avoidance of the salinity farthest from that of $34 \% \mathrm{~S}$.

Present experiments, in which continuous observations were made, show that differentials of as little as $4 \%$ ( $\equiv 12 \%)$ elicit avoidance behaviour in Carcinus maenas (Table 2, Fig. 2), though this may be apparent only after 4 to $5 \mathrm{~h}$ (Fig. 2) or even longer (Fig. 1b). In pairs of very low salinities (Table 3 ) it is clear that sustained halokinesis takes place. This occurs at salinities below about $17 \% \mathrm{~S}$ ( $\equiv 50 \% \mathrm{SW}$ ), well below the lower limit of the 'preferred' salinity of $27 \%$ S (三 $80 \%$ SW) defined by Thomas et al. (1981). However, $C$. maenas clearly distinguishes between pairs of salinities of as little as $4 \%$ difference at salinities above $17 \% \mathrm{~S}$ (Table 2), even though no statistically significant halokinesis is detected (Table 3). Presumably this is partly explained by the fact that any initial high halokinesis in crabs introduced into the lower salinity of a pair would be compensated for by low halokinesis when they had moved to a preferred salinity. Crabs given the choice of 9 and $34 \%$ S illustrate an extreme case of this (Tables $2 \& 3$ ). However, since control crabs given $34 \% \mathrm{~S}$ in both halves of a choice chamber all show spontaneous locomotor activity (Table 3), which in freshly collected crabs varies in a tidally rhythmic pattern (Naylor 1985), it seems likely that such spontaneous activity might also be a contributory factor in affecting salinity choice. More detailed temporal analysis is, therefore, required of salinity preference behaviour in crustaceans. It is necessary to distinguish between effects such as those described here for crabs acclimated in the laboratory, and 'responses' occurring in freshly collected crabs which show spontaneous circatidal and circadian rhythms of locomotion. Also, it is necessary to assess the effects of acclimation to low salinity on responses such as we describe here, and to consider the behavioural implications of physiological changes in ionic composition of the crab's haemolymph. In any event it is clear that in considering the responses of crustaceans to changes in salinity, neither physiological responses nor behavioural responses can be considered in isolation.

Acknowledgements. We are grateful to Mr G. P. Jones for help with the sampling, Mr D. A. Davies who built the actographs, Dr John Davenport for helpful discussion, and the Association of Commonwealth Universities for support to C.A.-A.

\section{LITERATURE CITED}

Bolt, S. R. L., Naylor, E. (1985). Interaction of endogenous and exogenous factors controlling locomotor activity rhythms in Carcinus exposed to tidal salinity cycles. J. exp. mar Biol. Ecol. 85: 47-56

Broekhuysen, G. J. (1936). On development, growth and distribution of Carcinides maenas (L.). Archs néerl. Zool. 2: 257-399

Crothers, J. H. (1967). The biology of the shore crab Carcinus maenas (L.). 1. The background - anatomy, growth and life history. Field Stud. 2: 407-434

Crothers, J. H. (1968). The biology of the shore crab Carcinus maenas (L.). 2. The life of the adult crab. Field Stud. 2: $579-614$

Dare, P. J., Edwards, D. B. (1981). Underwater television observations on the intertidal movements of shore crabs, Carcinus maenas, across a mudflat. J. mar. biol. Ass. U.K. 61: $107-116$

Davenport, J. (1972). Salinity tolerance and preference in the porcelain crabs Porcellana platycheles and Porcellana Iongicornis. Mar. Behav. Physiol. 1: 123-138

Davenport, J. (1985). Osmotic control in marine animals. Symp. Soc. Exp. Biol. 39: 207-244

Davenport, J. (1985). Environmental stress and behavioural adaptation. Croom Helm, London

Duval, M. (1925). Recherches physico-chimiques et physiologiques sur la milieu interieur des animaux aquatiques. Modifications sous l'influence du milieu exterieur. Annls Inst. océanogr., Monaco 2: 232-407

Hill, B. J. (1978). Activity, track and speed of movement of the crab Scylla serrata in an estuary. Mar. Biol. 47: 135-141

Lagerspetz, K., Mattila, M. (1961). Salinity reactions of some fresh and brackish water crustaceans. Biol. Bull. mar. biol. Lab., Woods Hole 120: 44-53

McLusky, D. S. (1970). Salinity preference behaviour in Corophium volutator. J. mar. biol. Ass. U.K. 50: 747-752

Muus, B. J. (1967). The fauna of Danish estuaries and lagoons. Distribution and ecology of dominating species in shallow reaches of the mesohaline zone. Medr Kommn Danm. Fisk-og Havunders. 5: 1-316

Naylor, E. (1962). Seasonal changes in a population of Carcinus maenas (L.) in the littoral zone. J. Anim. Ecol. 31: 601-609

Naylor, E. (1985). Tidally rhythmic behaviour of marine animals. Symp. Soc. Exp. Biol. 39: 63-93

Rankin, J. C., Davenport, J. (1981). Animal osmoregulation. Blackie, Glasgow

Taylor, A. C., Naylor, E. (1977). Entrainment of the locomotor rhythm of Carcinus by cycles of salinity change. J. mar. biol. Ass. U.K. 57: 273-277

Thomas, N. J., Lasiak, T. A., Naylor, E. (1981). Salinity preference behaviour in Carcinus. Mar. Behav. Physiol. 7: $277-283$

Warner, G. F. (1977). The biology of crabs. Elek Science, London

Wolff, W. J., Sandee, A. J. J. (1971). Distribution and ecology of the Decapoda Reptantia of the estuarine areas of the rivers Rhine, Meuse and Scheldt. Neth. J. Sea Res. 5: $197-226$ 